\title{
GNSS-based Location Determination System Architecture for Railway Performance Assessment in presence of local effects
}

\author{
C. Stallo, A.Neri, P. Salvatori, A. Coluccia \\ Consorzio RadioLabs, Corso d'Italia 19, 00198, Rome, Italy \\ L. Bonenberg, T. Moore \\ University of Nottingham \\ Triumph Road, NG72TU, Nottingham, U.K.
}

\author{
R. Capua, G. Olivieri, L. Gattuso \\ SOGEI, Via Mario Carucci 99, Rome, Italy \\ F. Rispoli \\ Ansaldo STS \\ Via Paolo Mantovani, Genoa, Italy
}

\begin{abstract}
GNSS plays a strategic role on the introduction of the Virtual Balise functionality and the train integrity. Thanks to GNSS, it could be possible to realize cost-effective solutions to increase the safety in the regional lines, where the traffic density is lower. The train position estimation is implemented taking into account that the train is constrained to lie on the track (i.e. track constraint). In this way, we can express the position in terms of the curvilinear abscissa (progressive mileage) of the track corresponding to the train position. However, the impact of local effects such as multipath, foliage attenuation and shadowing in the railway environment plays a crucial role due to the presence of infrastructures like platform roofs, side walls, tunnel entrances, buildings and so on close to the trackside. In the paper, we analyse the impact of those threats on the train GNSSbased position estimation performance. At this aim, several scenarios have been generated by using both real data acquired on a railway test-bed in Sardinia, and synthetic data generated in the lab through ad hoc multipath and foliage models.

A sensitivity analysis has been conducted, varying main scenarios parameters (e.g. height of obstacles, presence of trees and shadowing). The result of the performed analysis, in terms of availability, accuracy and integrity, are here presented. mitigations implemented by the ERTMS at system level are not considered since the attention is focused on GNSS only.
\end{abstract}

Keywords- GNSS (Global Navigation Satellite Systems), ERTMS (European Railway Traffic Management System / European Train Control System), AIMN (Augmentation and Integrity Monitoring Network).

\section{INTRODUCTION}

According with [1], [2], [3], the introduction of GNSS technology and the IP (Internet Protocol) based communication is the next frontier for the European standard for train control: ERTMS. Major benefits of such innovation rely in the possibility to reduce the maintenance and operational costs without losing in terms of system safety. This consideration leads to the possibility of a cost effective solution for the modernization of the regional low traffic density lines that in Europe represent a big market slice [4]. The big challenge in the adoption of the GNSS technology is represented by the fulfilment of the SIL 4 (Safety Integrity Level) requirement defined by Comité Européen de Normalisation Électrotechnique (CENELEC). With this scope, we have to achieve the same total hazardous failure rate of the traditional mechanical odometers [1], [5], [6], [7], [8]. To reach such high performance, the use of augmentation systems is highly recommended. In literature, different architectures have been proposed [9], [10]. Another important issue is related to SIS (Signal In Space) integrity assessment. A position solution by a satellite fault or strongly prejudiced by atmospheric or local effect as multipath, can lead to a Misleading Information. According to that, the adoption of an integrity monitoring network is mandatory. In literature, the integrity monitoring has been studied both in terms of RAIM (Receiver Autonomous Integrity Monitoring) [11], [12], [13], [14], and IMN (Integrity Monitoring Network) algorithms [10], [15], [16], [17].

The goal of this work is to evaluate the impact of the local effects (multipath, foliage and shadowing) on the train position estimation calculated through GNSS-based LDS (Location Determination System), taking into account the rail requirements. At this aim, real data acquired on a railway testbed in Sardinia (along Cagliari-San Gavino railway track) and synthetic data generated through multipath and foliage models (by using SPIRENT GSS8000 simulator) have been used. Real data were collected within the GSA (European GNSS Supervisory Authority) Horizon 2020 ERSAT EAV [20]. LA data, through the implementation of the 2-tiers integrity monitoring algorithm ([10]), have been included into the analysis.

The paper is organised as it follows. Section II describes the GNSS LDS railway reference architecture considered for the performance analysis in presence of local effects. Then, it shows the fault tree analysis applied to that architecture.

Section III reports the methodology adopted for evaluating the GNSS-LDS reference architecture performance in presence of multipath, shadowing and foliage through real data acquired on field and synthetic data. 
Section IV illustrates the results of the sensitivity analysis in terms of availability, accuracy and integrity, considering two main ERTMS operational phases: Full Supervision (FS) and Start of Mission (SoM). Finally, Section V reports the conclusions.

\section{GNSS LDS REFERENCE ARCHITECTURE FOR RAILWAY}

The Reference Architecture GNSS based LDS is composed of the following components:

- On Board Unit (OBU): it applies the Augmentation messages coming from the Radio Block Center (RBC) for calculating the train position;

- Radio Block Constituent (RBC): knowing the train position, it is in charge of defining and sending the Movement Authority to the OBU;

- SBAS (Satellite Based Augmentation System) Ground Services: the terrestrial services provided to the user by the SBAS Ground Segment (e.g. EDAS (EGNOS Data Access Service) for EGNOS (European Geostationary Navigation Overlay Service));

- Radio Communication Network: it is the rail communication network used by the rail operator for the communication between the RBC and the OBU;

- GPS and GALILEO Ground Services: ancillary services provided to the user by the GNSS Ground Segment (e.g. precise ephemeris, almanacs, geodetic reference frame parameters); an example of that is the IGS (International GNSS Service) RTS (Real Time Service) system for GPS and the GRSP (Geodetic Reference Service Provider) for GALILEO;

- high QoS (Quality of Service)/Security Communication Network: a high QoS (low latency, low number of lost packets) is needed between the GPS and Galileo Ground Services operators, SBAS Ground Services operators, external LA Network and the RBC (Radio block Centre) component of the Rail TCS system; furthermore, a high level of security is needed for Cyber-attacks counteraction.

- high integrity GNSS Reference Station Network: they implement an FDE (Fault Detection and Exclusion) algorithm in order to perform the first level of Integrity Monitoring on GNSS SIS and Reference Stations (RSs). In the current test-bed, a real-time 2-Tiers algorithm has been here operated, as it will be reported after.

Relevant architectural scheme is reported in Fig. 1. The LA architecture takes GNSS raw data from SBAS Ground Services (e.g. EDAS), and RSs belonging to external augmentation networks (external network) to be used for densification of a rail backbone network. Raw data are gathered through the data Acquisition block and fed into the integrity monitoring block. It is in charge of performing RS and SIS FDE. The candidate mean is the 2-Tiers algorithm [10], able to integrate SBAS RIMS raw data and RS raw data for performing the FDE. Relevant integrity parameters (e.g. B- values, probability of fault of RS, satellites and constellations) are calculated by the integrity parameters block. Anomalous ionospheric conditions are detected by the local atmospheric monitoring block. A generalized architecture, able to cover any kind of available high precision system in the future, starting from current GBAS (Ground Based Augmentation System) toward current Network RTK (Real Time Kinematic) and the incoming real-time PPP (Precise Point Positioning), has been studied (Fig. 2). With this scope, network ambiguities can be solved by the Control Centre. In the future, precise orbit and clocks estimation in real-time, as well as local ionospheric STEC (Slant Electron Content) estimation can be performed for PPP and integrity monitoring issues, respectively. A measurement correction component is in charge of calculating final corrections and sending them to the augmentation processing and messages generation for final corrections formatting in standard mode and sending to the TALS. GNSS precise ephemeris and clocks will be gathered from the IGS sites (SP3 (Standard Product \# 3) files). GRSP is currently not available.

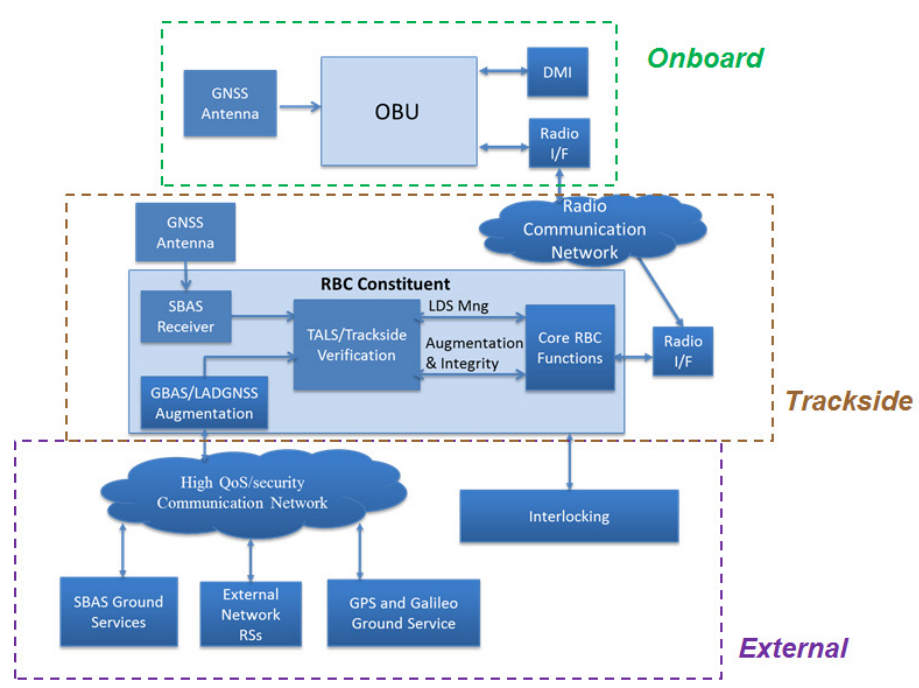

Fig. 1. System Reference Architecture

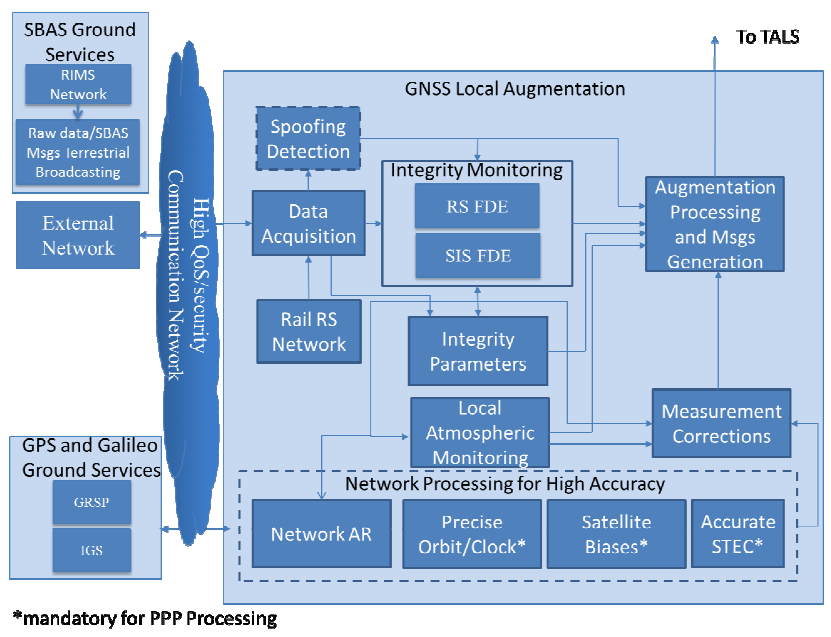

Fig. 2. LA Network 
Standard communication data formats (e.g. RTCM (Radio Technical Commission for Maritime Services)) and new proposed RTCM messages for integrity parameters messages, as well GBAS ones, are used for the communication among blocks. The reference architecture is a full instance able to cover any kind of available high precision system in the future, starting from current GBAS toward current Network RTK and the incoming Real-Time PPP. The LA architecture used for the performance analysis is a subset of the full architecture. It provides relevant safety-related functions (e.g. FDE, integrity parameters, measurement corrections and messages generation). They are the basic functions needed for implementing high demanding SIL 4 applications in different rail operation modes, e.g. SoM and FS and to assist the track discrimination. Then, the fault-tree analysis applied to the LDS GNSS-based reference architecture, starting from the UNISG Subset-088 specifications on ETCS Level 1 \& 2 ([21]), is shown. The initial apportionment of Tolerable Hazard Rate (THR) of 2e-9/hr is subdivided explicitly among main relevant hazards: Virtual Balise Detection Hazard (1e9/hr), Radio Subsystem Hazard (3.3e-10/hr) and Odometry Hazard (1e-10/hr). Virtual Balise Detection branch is added as a replacement of physical balises and BTM (Balise Transmission Module) subsystem. To be noted that the communication fault hazard appears at the second level, due to the relevance that it assumes for the transmission of Augmentation data. At Level 3, the classical equal subdivision between trackside and On-Board is obtained. The trackside branch at Level 4 includes the GNSS SIS/LA, where a THR of $4.5 \mathrm{e}-10 / \mathrm{hr}$ has been allocated. Concerning the LA fault, a THR of $2 \mathrm{e}-10 / \mathrm{hr}$ is allocated. Following a LA fault analysis carried out the RHINOS project [23], such a requirement can be met with appropriate integrity monitoring systems. Environmental effects are allocated at Level 3, with a relevant total THR of $0.5 \mathrm{e}-9 / \mathrm{hr}$. Among them, multipath allocation is 2e-10/hr. While ARAIM on-board integration can help in multipath rejection, a new mitigation system has to be designed for meeting the required THR. Such new system has been called Function B. It will be one of the major tasks for the future to study such On-Board mitigation techniques. The relevant Fault Tree is reported in Fig. 3.

\section{ReAl TESt Bed AND Simulated Data GENERATION}

The impact of the local effects (multipath, foliage and shadowing) on the train position estimation, as calculated by the GNSS-based LDS (Location Determination System), taking into account the rail requirements, has been verified through the use of both real data, collected in a railway test environment and synthetic simulated data. Laboratory-based simulation allows conducting testing without the uncertainties of field-testing, by the ability to define and control the whole scenario. Real data were collected along the pilot line Cagliari-San Gavino railway track in Italy, using train's onboard receiver. Beidou, SBAS) and multi-frequency geodetic receivers and multipath-resistant choke-ring antennas. Augmentation RSs deployed along the route consisted of multi-constellation (GPS, GLONASS GALILEO).

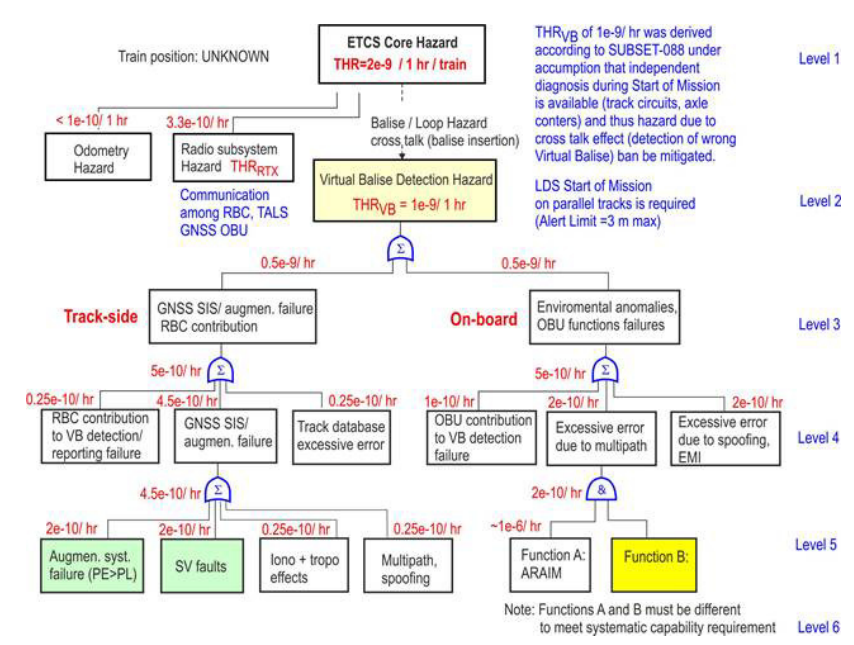

Fig. 3. Fault Tree

These data were used to simulate the shadowing effect in an urban railway scenario (equivalent to OBU data in SoM phase with reduced satellites visibility), generated by the VIRGILIO simulator. The multipath and foliage effects were tested using a low-latency, high-rate multi-channel multi-GNSS Spirent GSS8000 simulator. It is generating realistic RF signal in ultra-high dynamic conditions. All simulation parameters are controlled by the SimGen graphical interface [18]. Figure 4 shows generated signals strength (including multipath echoes), train trajectory and skyplot in one of the scenarios created.

RF signals for GPS (L1 and L2 frequency) and GALILEO (E1 and E5 frequency) were generated based on the information collected along the Cagliari-San Gavino railway track in Italy on the 06 April 2016 15:00-16:00 GPS time. A GPS constellation matching the one recorded on the day and a fully operational GALILEO constellation were simulated. Atmospheric and ionospheric conditions were reproduced using Spirent build-in models. The observed satellites were subject to obstruction and multipath (direct signal and between one to three echoes) from the vertical planes, representing obstructions on both sides of the train. An additional echo channel with fixed offset was applied to the code and carrier phase for GPS satellite 24. An additional echo channel with Doppler offset was applied to GALILEO satellite 27. An advanced simulation of multipath generated by obstructions and foliage close to the track, was created using the Spirent's mobile multipath model.

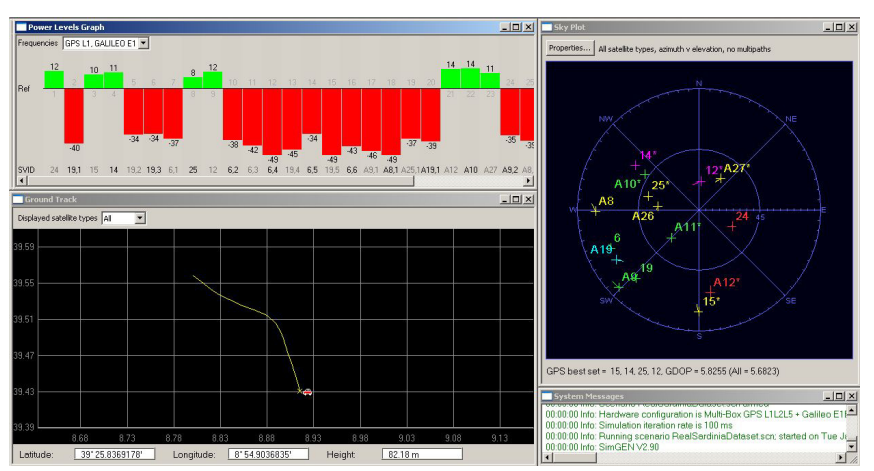

Fig. 4. SimGen user interface showing scenario setup 
This model allows to define the following characteristics of a 3D environment:

- obscuring all satellite signal;

- open sky;

- multipath (direct signal and echoes);

- multipath with blocking the direct signal (only echoes).

Depending on the satellite angle, Rician fading was applied to the direct signal, and Rayleigh delay function to the reflected one. Rician fading can be estimated from the following equation:

$$
f_{\text {Rician }}(v)=2 K v \exp \left[-K\left(v^{2}+1\right)\right] I_{0}(2 K v)(1)
$$

where $\mathrm{K}$ is the elevation dependent constant, representing the ratio of direct to reflected signal strength, and $I 0$ is the 0th order modified Bessel function of the first kind. This function is only applied if the received voltage, relative to the direct signal power, is positive. Otherwise, the direct signal is not modified [18]. Reflected signals were modelled using the Rayleigh fading, consisting of a deterministic mean power function, an amplitude noise function (Rayleigh) and a delay function.

The mean power function, in $\mathrm{dB}$, is defined as:

$$
P_{h}(\tau)=P_{h}(0)-d \tau
$$

where $\mathrm{Ph}(0)$ and $\mathrm{d}$ are determined by the user. The Rayleigh noise function is defined as

$$
f_{R}(v)=2 K v \exp \left[-K v^{2}\right]
$$

and the delay on the echo channel is calculated using exponential distribution:

$$
f_{\text {exp }}(\tau)=\frac{1}{b} \exp \left[-\frac{\tau}{b}\right]
$$

Where $\mathrm{b}$ and the function's upper limit are defined by the user. Additionally, each multipath echo were simulated on an independent channel, with carrier Doppler offset applied to non-primary echoes using following equation:

$$
f_{\text {off }}(v)=B+\Psi v \cos \alpha_{e}
$$

where $\mathrm{B}$ is the initial bias, $\mathrm{v}$ is the user velocity, $\Psi$ is the velocity offset conversion factor, and $\alpha_{e}$ is the satellite elevation angle.

Figure 5 demonstrates a 3D model used in the scenario with azimuth of 0 indicating the direction of travel. Rapidly varying features above 25 degrees elevation, chosen to match the previous scenario, simulate vegetation. Openings, on azimuths -30 to 30 and 160 to -160 , simulate open environment in the direction of the train travel. Train body multipath was not simulated.

\section{PERformance ANAlysis}

Tests have been carried out using real GNSS raw data registered on board of a Pilot Train in the Cagliari-San Gavino track, as well as simulated data.

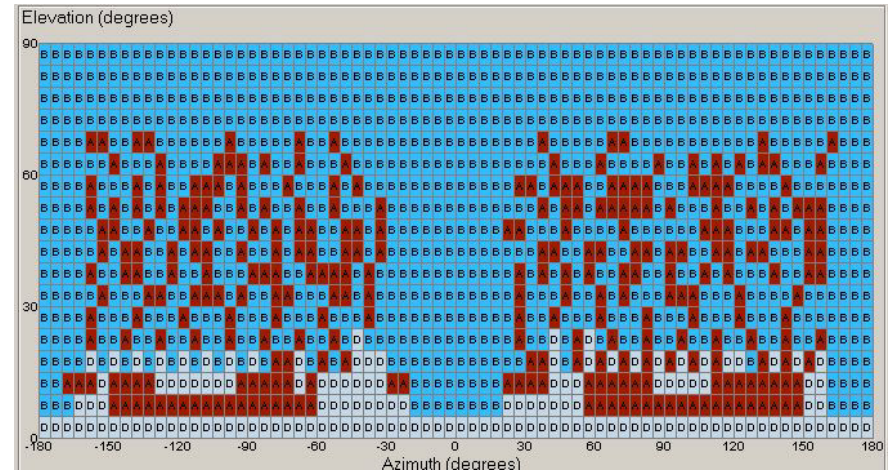

Fig. 5. 3D visualisation of the obstructions and foliage generated multipath

The ERSAT LA infrastructure, composed by five RSs and a Control Centre in Rome (implementing the 2-Tiers integrity monitoring), was used for simulating integrity faults and providing relevant corrections. The simulation architecture is shown in Fig. 6.

Accuracy and integrity analysis are performed through the VIRGILIO simulator. It is a complete multi-constellation software simulator developed from RadioLabs for the GNSS LDSs for rail. It supports $\mathrm{H} / \mathrm{W}$ in the loop simulation, and has high scalability through distributed simulation in cloud environment. The VIRGILIO Simulator Architecture is reported in Fig. 7. With its modular design, VIRGILIO is transparent to the number and location of processing nodes. It can work in two modalities:

- centralized processing: all the simulated components run in the same node; data exchange occurs in memory;

- distributed processing: data exchange between modules is allowed also through a network protocol (UDP/IP based). Therefore, VIRGILIO can be set up with the various components running on different nodes. The distribution scheme can be easily adapted to the number of nodes, up to a maximum degree of distribution with each functional component running on a dedicated processing element.

The two main rail operational phases, SoM, starting from an unknown position, and FS have been considered.

The GRDNet (GNSS R\&D Network) Control software has been used for LA simulations. It is able to perform real-time and post-processing operations for RTK/NRTK and implements the 2-Tiers algorithm.

For the SoM, the AL (Alert Limit) has been set to $3 \mathrm{~m}$, while for the FS to $12 \mathrm{~m}$. For meeting the above AL requirement, all the analysis for the SoM have been carried out through RTK processing.

A THR of $10-9 / \mathrm{h}$ for the whole system (satisfying SIL 4 requirements) has been imposed for Protection Level (PL) calculation and relevant integrity analysis. LA can therefore achieve the $4.5 * \mathrm{e}-10 / \mathrm{h}$ THR requirement, as reported in [18].

Concerning the SoM phase, the parallel track discrimination has been carried out through two methods: the track constrained algorithm developed in [19] and the classical RTK method. 


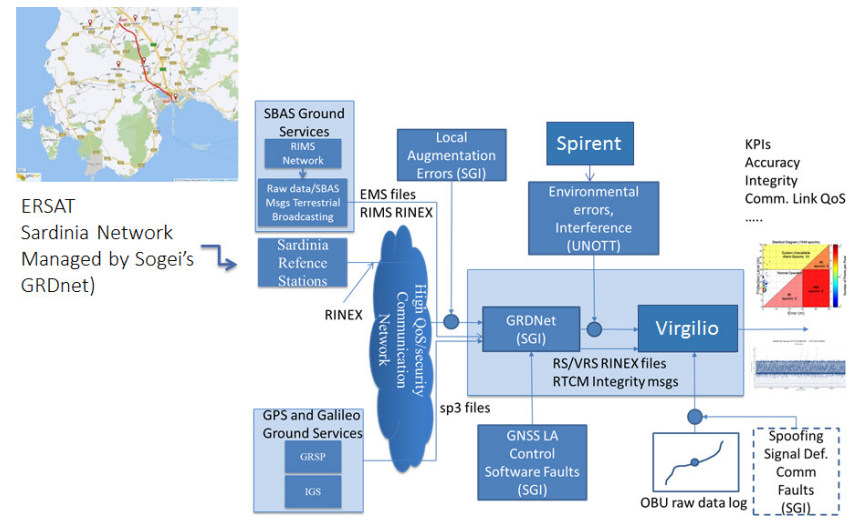

Fig. 6. Performance analysis simulation architecture

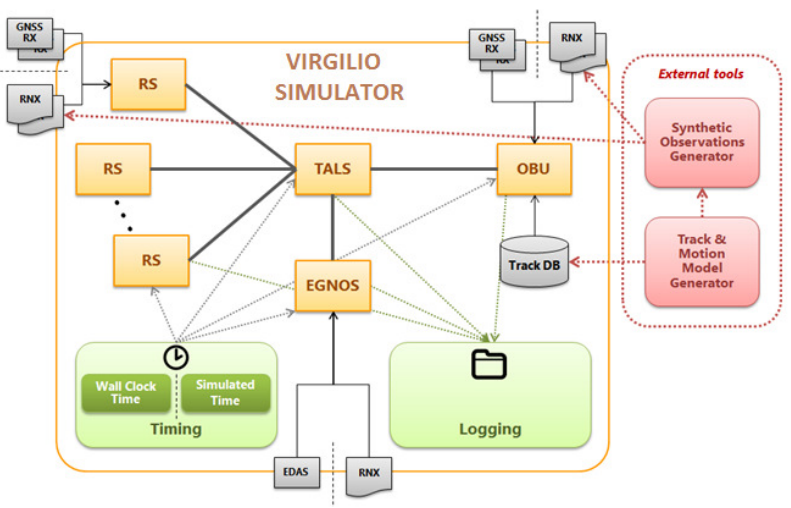

Fig. 7. VIRGILIO simulator architecture

The first method allowed a relevant robustness in track discrimination, based on multi-hypothesis analysis through the Melbourne-Wubbena raw measurements combination ([19]). A very low probability of fault in track discrimination has been envisaged in nominal conditions.

The application of RTK, with simulated data including weak multipath conditions, leaded to floating and fixed solutions, with full availability is achieved.

Concerning the FS case, the normal operation analysis, carried out through real receiver raw data measurement on the Cagliari-San Gavino railway track, reports an availability of 0.99932 due to the GNSS only.

The mean position error is in this case of $1 \mathrm{~m}$, with a standard deviation of $0.4 \mathrm{~m}$.

Relevant Results for the nominal case analysis are reported in TABLE I.

Local effects have been investigated through sensitivity analysis about shadowing, multipath, and foliage attenuation. The impact of shadowing has been analysed in SoM through an incrementally increasing cut-off angle with three possible levels. For the three cases (light, medium, severe), a full availability is estimated, while the position error can be in the order of $0.2-0.4 \mathrm{~m}$, with a standard deviation ranging from 0.1 to $0.3 \mathrm{~m}$. Also, if not relevant for the integrity performances, a high level of shadowing can provide a significant contribution to the error budget.
TABLE I. Test CASE Results Summary

\begin{tabular}{|c|c|c|c|}
\hline TEST CASE & AVAILABILITY & $\begin{array}{c}\text { MI } \\
(\%)\end{array}$ & $\begin{array}{c}\text { NO } \\
(\%)\end{array}$ \\
\hline $\begin{array}{c}\text { NORMAL OPERATION } \\
\text { (SOM) }\end{array}$ & 1 & 0 & 100 \\
\hline $\begin{array}{c}\text { NORMAL OPERATION } \\
\text { (FULL SUPERVISION) }\end{array}$ & 0.99932 & 0.00 & 99.93 \\
\hline
\end{tabular}

In the performed tests, the Stanford analysis revealed that till 32 degrees of shadowing, the SoM safety requirements can still be met.

The impact in terms of integrity is reported in the Stanford Plot Fig. 8 for a shadowing angle of $32 \mathrm{deg}$.

Raw data with injected multipath errors have been generated for the rover receiver, while RSs modeled without any interferences. For the scope of reproducing as much as possible the real pilot scenario for the whole Cagliari-San Gavino rail track, Spirent simulation run with the same model of rover and RS receivers. Rover data have been reproduced with multipath effect combining vertical plane obstruction and reflection. In order to carry out a sensitivity analysis, an increasing wall has been placed on both sides of the rail track, ranging from 0.5 to $2 \mathrm{~m}$ above the antenna height with multipath added to two echo channels with fixed attenuation and range offset from direct signal.

The system availability decreases to 0.99735 , while the percentage of MI (Misleading Information) is in the order of $6.3 \%$. The induced position error is about of $4.7 \mathrm{~m}$, with a standard deviation of $2.7 \mathrm{~m}$. It confirms the relevant impact of multipath on system availability and position accuracy. Relevant test configuration and Stanford plots are reported in Fig. 9 (the letters indicate the simulated height of the wall above the roof of the train for each successive 10 minutes time interval). For analysing the effect of foliage attenuation, the disturbance of trees added on the top of the wall-generating multipath, has been injected into the previous analysis.

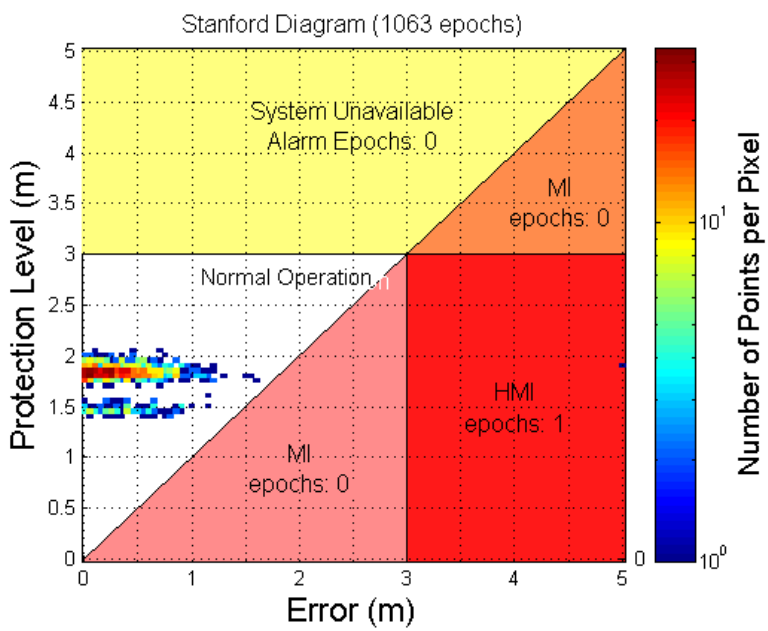

Fig. 8. Shadowing Effect Stanford Plot 


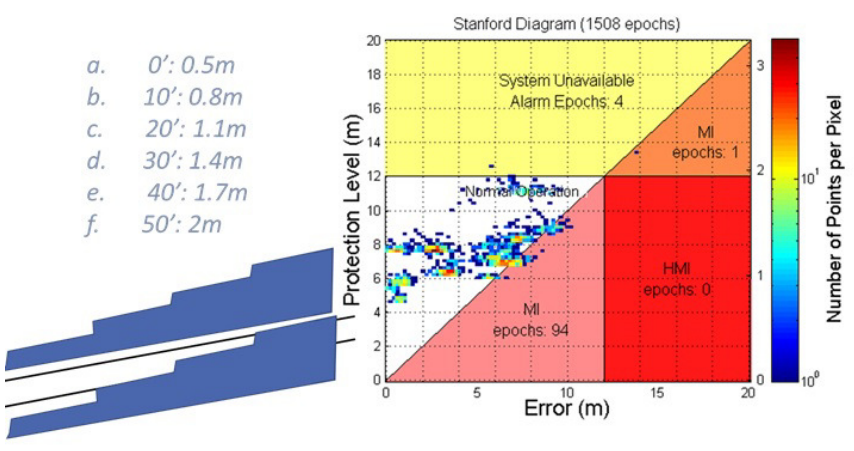

Fig. 9. Multipath Effect Stanford Plot

In this case, the availability is in the order of 0.99601 , while the MI percentage increase up to $6.72 \%$, and the epochs when the system is in nominal operations reduces to $92.88 \%$. The foliage attenuation, together with multipath, as largely expected by the GNSS literature and surveying experiences, introduces a relevant error in the order of 4, $5 \mathrm{~m}$, with a standard deviation of $2.7 \mathrm{~m}$. It is therefore highly recommended to choose the location of Virtual Balises in areas not highly affected by multipath or characterized by the presence of trees around the rail track. Relevant integrity analysis results are reported in a Stanford Plot in Fig. 9. Relevant performance analysis results are summarised in TABLE II.

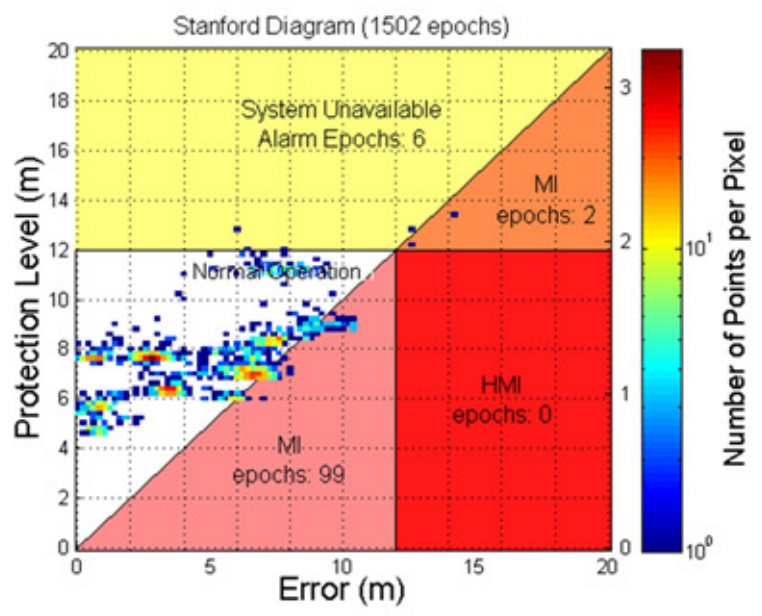

Fig. 10. Multipath and Foliage Attentuation Stanford Plot

TABLE II. Performance AnAlysis Test CASE Summary

\begin{tabular}{|c|c|c|c|}
\hline TEST CASE & AVAILABILITY & $\begin{array}{c}\text { MI } \\
(\%)\end{array}$ & $\begin{array}{c}\text { NO } \\
(\%)\end{array}$ \\
\hline $\begin{array}{c}\text { URBAN AREA SEVERE } \\
\text { SHADOWING (START OF } \\
\text { MISSION) }\end{array}$ & 1 & 0 & 100 \\
\hline $\begin{array}{c}\text { URBAN AREA SEVERE } \\
\text { MULTIPATH (FUL } \\
\text { SUPERVISION) }\end{array}$ & 0.99735 & 6.30 & 93.44 \\
\hline $\begin{array}{c}\text { URBAN AREA SEVERE } \\
\text { MULTIPATH AND FOLIAGE } \\
\text { (FULL SUPERVISION) }\end{array}$ & 0.99601 & 6.72 & 92.88 \\
\hline
\end{tabular}

\section{CONCLUSIONS}

A GNSS performance analysis in rail operational environment has been carried out to investigate the impact of local effects in terms of availability, accuracy and integrity of the system. A preliminary fault analysis has been carried out, starting from relevant ETCS (European Train Control System) standardisation documents. The concept of a GNSS-based Virtual Balise as well as the definition of AIMN-OBU system reference architecture have been shown. A relevant THR (2e$10 / \mathrm{hr}$ ) allocated to the local effects (in particular multipath) has been derived through the fault-tree analysis applied to the reference LDS GNSS-based system architecture.

Since multipath is the most significant integrity risk to adopt GNSS based train localization for rail, and little heritage can be derived from the aviation applications, a specific solution for rail is needed. Future work is underway as follow up of the RHINOS projects where we developed a 2-levels multipath detection mechanism. The goal is to predict and mitigate the bounded errors arising from the multipath along the railways line for minimising the errors of the Virtual Balise position. To this aim, innovative techniques based on a-priori predictability, intelligent antennas, deep learning and use of GNSS independent means are being developed for the ERTMS application.

\section{ACKNOWLEDGMENT}

The authors wish to thank Salvatore Sabina from Ansaldo STS, Ales Filip from University of Pardubice, Per Enge, Sam Pullen and Sherman Lo from University of Stanford for their support to this research.

This research was partly funded by H2020-Galileo-GSA 20142015687399 RHINOS (Rail High Integrity Overlay System) project and Italian regional VIRGILIO (Virtual InstRuments for GNSS AugmentatIon and LocalizatIOn) project co-funded by LazioInnova.

\section{REFERENCES}

[1] A. Neri, A. Filip, F. Rispoli, and A.M. Vegni, "An Analytical Evaluation for Hazardous Failure Rate in a Satellite-based Train Positioning System with reference to the ERTMS Train Control Systems", ION GNSS 2012, Nashville, TN, U.S.A.

[2] ERTMS (European Rail Traffic Management System): www.ec.europa.eu/transport/modes/rail/index.

[3] ERTMS LEVELS, Different ERTMS/ETCS Application Levels to Match Customers' Needs, Factsheets. Available online.

[4] Salvatori, P.; Neri, A.; Stallo, C.; Rispoli, F., "Ionospheric incremental delay models in railway applications," in Metrology for Aerospace (MetroAeroSpace), 2015 IEEE , vol., no., pp.251-255, 4-5 June 2015.

[5] Palma, V.; Salvatori, P.; Stallo, C.; Coluccia, A.; Neri, A.; Rispoli, F., "Performance evaluation in terms of accuracy positioning of local augmentation and integrity monitoring network for railway sector,"Metrology for Aerospace (MetroAeroSpace), 2014 IEEE , vol., no., pp.394,398, 29-30 May 2014.

[6] A. Filip, F. Rispoli, "SIL 4 Compliant Train Location Determination System Based on Dual-Constellation EGNOS-R Interface for ERTMS/ETCS", CERGAL 2014, Dresden, 8-9 July 2014.

[7] A. Filip, and F. Rispoli, "Safety concept of GNSS based train location determination system SIL 4 compliant for ERTMS/ETCS," in Proc. of 
ENC-GNSS 2014, Rotterdam, Netherlands.

[8] A. Filip, J. Beugin, and J. Marais, "Safety Concept of Railway Signaling Based on Galileo Safety-of-Life Service," COMPRAIL, Toledo, Spain, Sept 15-17, 2008, pp. 103-112.

[9] Salvatori, P.; Neri, A.; Stallo, C.; Palma, V.; Coluccia, A.; Rispoli, F., "Augmentation and Integrity Monitoring Network and EGNOS performance comparison for train positioning," Signal Processing Conference (EUSIPCO), 2014 Proceedings of the 22nd European , vol., no., pp.186,190, 1-5 Sept. 2014.

[10] Neri, A.; Capua, R.; Salvatori, P., "High Integrity Two-tiers Augmentation Systems for Train Control Systems," ION Pacific PNT 2015, 2015, 20-23 April 2015.

[11] Muhammad, B.; Cianca, E.; Salonico, A.M., "Multi GNSS Advanced RAIM: An availability analysis," in Metrology for Aerospace (MetroAeroSpace), 2014 IEEE, vol., no., pp.28-33, 29-30 May 2014.

[12] Joerger, M.; Pervan, B., "Solution separation and Chi-Squared ARAIM for fault detection and exclusion," in Position, Location and Navigation Symposium - PLANS 2014, 2014 IEEE/ION, vol., no., pp.294-307, 5-8 May 2014.

[13] Blanch, J.; Walter, T.; Enge, P.; Kropp, V., "A simple position estimator that improves advanced RAIM performance," in Aerospace and Electronic Systems, IEEE Transactions on , vol.51, no.3, pp.2485-2489, July 2015.

[14] Blanch, J.; Walter, T.; Enge, P., "Satellite Navigation for Aviation in 2025," in Proceedings of the IEEE , vol.100, no.Special Centennial Issue, pp.1821-1830, May 132012.

[15] S. Matsumoto, S. Pullen, M. Rotkowitz, and B. Pervan, "GPS Ephemeris Verification for Local Area Augmentation System (LAAS) Ground Stations", in Proc. of ION GPS 2009, September 14-17, 2009, Nashville, TN, USA.

[16] J. Blanch, T. Walter, P. Enge., "Fast Multiple Fault Exclusion with a Large Number of Measurements", in Proc. of Institute of Navigation (ION) International Technical Meeting, 2015, Dana Point, California., USA.

[17] Palma, V.; Salvatori, P.; Stallo, C.; Coluccia, A.; Neri, A.; Rispoli, F., "Performance evaluation in terms of accuracy positioning of local augmentation and integrity monitoring network for railway sector," in Metrology for Aerospace (MetroAeroSpace), 2014 IEEE , vol., no., pp.394-398, 29-30 May 2014.

[18] Spirent SimGen Softtware User Manual DGP00686AAA, 2013

[19] Performance Requirements for Interoperability, UNISIG SUBSET-041.

[20] A. Neri, R. Capua, P. Salvatori "Track constrained RTK for railway applications", Proc. of ION Conference, 2016, Portland, US.

[21] ERSAT-EAV Website, http://www.ersat-eav.eu/.

[22] ETCS Application Levels 1 \& 2 - Safety Analysis, UNISIG SUBSET088.

[23] RHINOS Website, http://www.rhinos-h2020.org/.

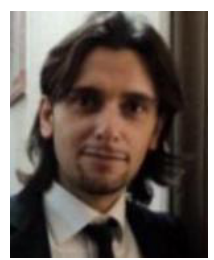

Cosimo STALLO obtained cum laude the Ph.D in Microelectronics and Telecommunications at Electronic Department of Engineering Faculty of University of Rome "Tor Vergata" in 2010. Since 2011 he is Professor for the course on Satellite Navigation at Master of Science on "Advanced Satellite Communication and Navigation Systems" of University of Rome Tor Vergata. Since 2013-14, he is tutor for the course on Communication Systems at University of Trento, Italy. Since February 2010, he is the Chair of the Space Systems Technical Panel of the IEEE AESS. Since 2012 he is a senior Researcher at RadioLabs Consortium, where he has been/is involved in the technical committees of different GNSS projects in the railway sector as ESA IAP 3 InSat (Train Integrated Safety Satellite System), ESA IAP SBS-RailS (Space Based Services for Railway Signalling), H2020 GSA ERSAT-EAV and H2020 GSA RHINOS (Railway High Integrity Navigation Overlay System). Currently, he is the project manager of an Italian regional project VIRGILIO (Virtual InstRuments for GNSS AugmentatIon and LocalizatIOn) and ESA GSTP Element 2-Competiteveness DB4RAIL (Digital Beamforming for Rail). $\mathrm{He}$ is co-author of about 60 papers on international journals/transactions and proceedings of international conferences.

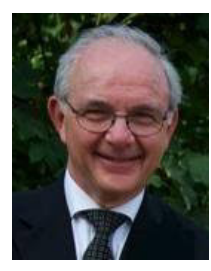

Alessandro NERI is Full Professor in Telecommunications at the Engineering Department of the ROMA TRE University. In 1977 he received the Doctoral Degree in Electronic Engineering from "Sapienza" University of Rome. In 1978 he joined the Research and Development Department of Contraves Italiana S.p.A. where he gained a specific expertise in the field of radar signal processing and in applied detection and estimation theory, becoming the chief of the advanced systems group. In 1987 he joined the INFOCOM Department of "Sapienza" University of Rome as Associate Professor in Signal and Information Theory. In November 1992 he joined the Electronic Engineering Department of ROMA TRE University as Associate Professor in Electrical Communications, and became Full Professor in Telecommunications in September 2001. His research activity has mainly been focused on information theory, signal theory, signal and image processing, location and navigation technologies, and their applications to both telecommunications systems and remote sensing. Since December 2008, Prof. Neri is the President of the RadioLabs Consortium, a non-profit Research Center created in 2001 to promote tight cooperation on applied research programs between universities and industries.

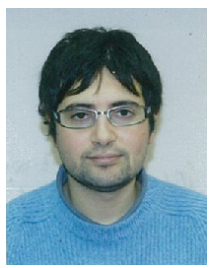

Pietro SALVATORI received a Ph.D. degree in Applied Electronics in May 2017 at the University of Roma TRE, Rome, Italy. He obtained the $1^{\text {st }}$ level degree in Electronic Engineering in 2010 and a $2^{\text {nd }}$ level degree cum laude in Information and Communication Technology Engineering in 2013 both at the University of Roma TRE, Italy. In 2013, he collaborated with RadioLabs consortium, carrying out research activities in the GNSS-based train control system. In January 2014 he joined the PhD program in Applied Electronics at the University of Roma TRE obtaining the title in May 2017. Currently he is employed at RadioLabs headquarter as Satellite Navigation System Researcher focusing on high integrity positioning systems for ground transportation domain.

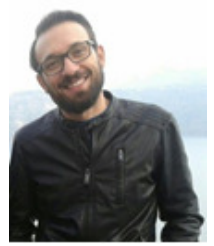

Andrea COLUCCIA is attending a Master's Degree in telecommunication engineering at the University of Rome 2 "Tor Vergata". He is received the Master of Science in Advanced Communications and Navigation Satellite System at the University of Rome 2 "Tor Vergata" and the bachelor of science in Telecommunications engineer at the University of Salento. He is now collaborating with Radiolabs since 2012, where he has been involved projects: ESA IAP 3InSat, ESA IAP SBS-RailS, H2020 GSA ERSAT-EAV and H2020 GSA RHINOS, H2020 GSA STARS, Italian regional project VIRGILIO. Currently, he is the project engineer for ASI project RAMPS. In November 2009, until to June 2013, he joined to research group of University of Rome 2 "Tor Vergata", where he gained experience in the prototyping of real time systems on ARM, microcontroller and FPGA platforms, In September 2008, until to December 2013, he joined to Navigation satellite Business Unit of Thales Alenia Space - Italia. In this period, he participated ASI projects PRESAGO.

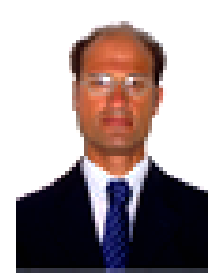

Roberto CAPUA received a Master Degree in Electronic Engineer. He has a consolidated background in the field of GNSS applications Research and Development for Public and Private Organisations. He worked on most important European Commission Programmes on Galileo design and applications. He was a Program Manager on satellite navigation applications for an important European Satellite Service Provider. His areas of activity include advanced high precision GNSS and Augmentation Systems, GNSS Software Receiver and GNSS surveying for cadastral and mapping applications. He worked on the development of hardware and software navigation and communication technologies for Road, Inland waterway, Aerospace and Surveying. He is currently responsible for GNSS R\&D for Sogei, where he is managing a GNSS Network for Cadastral Purposes and the GNSS SDR development project. He is furthermore delegate for his company in the Galileo Services Association and RTCM SC-104 Committee, where he chairs the Integrity Monitoring for High Precision Application WG. 


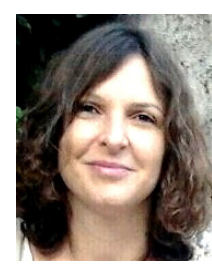

Giorgia OLIVIERI has a Master Degree in Environmental Engineering. Her degree thesis was about the development of a scientific software for the orthorectification of satellite images at high resolution at geodesy and geomatics department. The first project she worked on was the realization of street cadastre. She consolidated her background in geomatics and geodesy being involved in activities for managing GNSS data for cadastral purposes and precise positioning applications. She works on activities regarding GNSS Network control center within Galileo project and GNSS permanent network datum definition. She participated to Horizon 2020 projects ERSAT EAV, ERTMS on Satellite Enabling Application Validation and RHINOS Railway High Integrity Navigation Overlay System. Currently she is engineer in Sogei GNSS R\&D team.

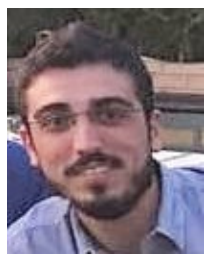

Luca GATTUSO received his MSc Degree in Telecommunication engineering from University of Reggio Calabria "Mediterranea", Italy, in 2007. In 2008 he participate to a research project about the realization of a middleware for QoS and vertical handovers managing in a heterogeneous $4 \mathrm{G}$ network scenario. He received a Master in Advanced Systems of Satellite Communication and Navigation from University of Rome "Tor Vergata", Italy, in 2010. Then he joined the R\&D GNSS group in Sogei S.p.A. where he currently works. His main area of activity is the design and development of GNSS Software Defined Radio receivers for highprecision positioning.

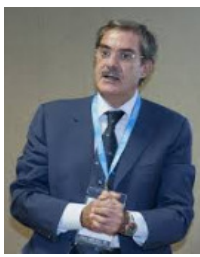

Francesco RISPOLI joined Ansaldo STS in 2011 and is the Manager for train control system's satellite technology and Director General of Radiolabs. Since 2011 he was involved in the innovation projects with the European Space Agency (ESA) and the European GNSS Agency (GSA). Francesco has chaired the Working Group for the satellite activities of the European Next Generation Train Control System project with the rail and satellite stake-holders.In 2012 he launched with RFI (Italian Railways Infrastructure Manager) the ERSAT pilot line with GNSS and satcom tested for integration into the ERTMS system. He is board Director of Galileo Services Association coordinating the satellite applications for rail. From 2005 he was the Chief New Initiatives at Telespazio and previously Vice President Multimedia Business Unit with Alenia Spazio. Francesco holds a doctoral degree in Electronic Engineering (Polytechnic of Turin 1978) and a post-graduate Master in Applied Electromagnetism (University La Sapienza in Roma 1980). In 2012 he was awarded the Finmeccanica Innovation Prize and the Italian Prize of Prize with a satellitebased innovation for train control systems.

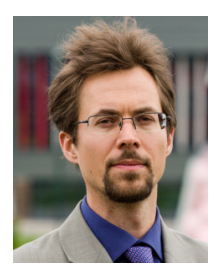

Lukasz BONENBERG is a Senior Experimental Officer at the University of Nottingham, responsible for teaching and research in the area of precise positioning, navigation and GNSS. Lukasz received his $\mathrm{PhD}$ from the University of Nottingham, looking at the deep integration of GPS and terrestrial pseudolite signals. Lukasz participated in the UK and European research projects looking at precise positioning, navigation and sensor fusion. He is Member of the Institute of Navigation, Corporate Member of Chartered Institute of Civil Engineering Surveyors and Member of Association for Geoinformatics, GeoIT and Navigation e.V. His current research interest includes applications of GNSS, low-cost navigation, raw GNSS observation from Android devices and sensor fusion. He is actively involved with work of GNSS Raw Measurements Task Force, coordinated by the European GNSS Agency (GSA). Lukasz is enthusiastic about the promotion of GNSS and navigation, through teaching, international workshops, lectures, seminars and hackathon.
Terry MOORE is Director of the Nottingham Geospatial Institute (NGI) at the University of Nottingham; where he is the Professor of Satellite Navigation.He has many years of research experience in surveying, positioning and navigation technologies and is a consultant and adviser to European and UK government organisations and industry. He is a Fellow, and a Member of Council, of both the Institute of Navigation (ION) and of the Royal Institute of Navigation (RIN). In 2013 was awarded the RIN Harold Spencer-Jones Gold Medal, and in 2017 the ION Johannes Kepler Award. 